Original Research

\title{
The Development of Model Family-Centered Empowerment on Caring for Children with Leukemia
}

\section{Yuni Sufyanti Arief', Nursalam Nursalam¹, I Dewa Gede Ugrasena²,Shrimarti Rukmini Devy ${ }^{3}$ and Eileen Savage ${ }^{4}$}

${ }^{1}$ Faculty of Nursing, Universitas Airlangga, Kampus C Mulyorejo, Surabaya, Indonesia

2 Faculty of Medicine, Universitas Airlangga, Jl. Prof. Dr. Moestopo 47, Surabaya, Indonesia

3 Faculty of Nursing, Universitas Airlangga, Kampus C Mulyorejo, Surabaya, Indonesia

${ }^{4}$ School of Nursing and Midwifery, University College Cork, Cork, Ireland

\begin{abstract}
Introduction: Children with leukemia desperately need serious attention, commitment and it is a hard struggle for family members. Powerlessness experienced by the family will affect the ability of the families to provide care for their children. Many factors can affect the empowerment of families in providing care to their families
\end{abstract}

Methods: The purpose of this study was to develop a family-centered empowerment model related to the family's ability to care for their child suffering from leukemia. The research design used was an explanation survey. The sample consisted of 140 families with children suffering from leukemia in the pediatric ward of Dr. Soetomo Hospital.

Results: The family-centered empowerment model was formed from the family factor, patient factor and nurse factor. The greatest effect was on the nurse factor, with the $\mathrm{T}$ statistic value $=6.590$.

Conclusion: Family factors and nurse factors need to be taken into account in familycentered empowerment. The patient factor has little influence on family empowerment in relation to caring for children. More research is needed on familycentered empowerment models in relation to their ability to care for children with leukemia. For example, a nurse providing a nursing intervention, especially a pediatric nurse, in relation to empowering a parent at the time of caring for their child with leukemia.

\section{ARTICLE HISTORY}

Received: March 02, 2018

Accepted: July 24, 2018

\section{KEYWORDS}

family; empowerment; family factor; leukemia

\section{CONTACT}

Yuni Sufyanti Arief \yuni sa@fkp.unair.ac.id $\Xi$ Faculty of Nursing, Universitas Airlangga Kampus C Mulyorejo, Surabaya, Indonesia

Cite this as: Arief, Y., Nursalam, N., Ugrasena, I., Devy, S., \& Savage, E. (2018). The Development of Model FamilyCentered Empowerment on Caring for Children with Leukemia. Jurnal Ners, 13(1), 98-105. doi:http://dx.doi.org/10.20473/in.v13i1.7774

\section{INTRODUCTION}

Every child with a chronic illness such as leukemia grows and develops in a unique family and cultural environment with many different variations. With children with chronic health conditions, it is often assumed that meeting the health needs of the children and sustaining their family life are two major challenges faced by the families (Deatrick \& Knafl, 1990; Dunst, 2011; Wuest \& Stern, 1991).

Families and children with chronic health conditions often feel helpless when trying to meet their child's health care needs and when trying to sustain their family life (Popp, Conway, \& Pantaleao,
2015). Based on the results of the interviews with mothers whose children were being treated for leukemia, related to the needs of childcare, the mothers stated that much of the daily health care advice is time-consuming, unpleasant, and that it felt burdensome. Family empowerment is an intervention that nurses can use to help families (Wright \& Leahey, 2000). These interactive interventions are designed to help the family through a process of empowerment, consisting of several stages that can increase trust and family decisionmaking to allow them to work better with health professionals (Johansson, 2006). Activities are based on assumptions that everyone has the power, 
capability and capacity to grow and become more competent.

Family empowerment is influenced by several factors such as the demands of care, family factors, patient factors and health care factors (Jones, Winslow, Lee, Burns, \& Zhang, 2011). The constituent attributes of family empowerment can be assessed using self-efficacy, motivation, acceptance of threats, responsibility, respect, and care. The expected outcomes for families with such empowerment include the ability to negotiate with health professionals, minimising the effects of chronic conditions on children and their siblings, rearranging the family roles and responsibilities, satisfying their child's health care needs, and lowering their use of health care and costs (Chiu, Wei, Lee, Choovanichvong, \& Wong, 2013).

Integrated and holistic cancer prevention should involve all of the components of the family factor because the needs of pediatric patients with cancer are complex, including the need to be pain-free, the need for attention, and the need for psychological support (Elcigil \& Conk, 2010). To help people with cancer thoroughly, it takes serious effort and the family role is very important. Therefore, it is important to consider whether the Family-Centered Empowerment Model can improve the family's ability to treat children with leukemia.

\section{MATERIALS AND METHODS}

This research used an explanatory survey research design and was conducted in the Pediatric Ward of Dr. Soetomo Hospital Surabaya in the period June to September 2017. The population in this study consisted of families that have children suffering from leukemia in the pediatric ward, with a large sample of 140 respondents The sampling technique in this study was the consecutive method. The selection of samples was according to the criteria. The inclusion criteria in this study was mothers of pre-school-aged children with leukemia > 1 year who were undergoing chemotherapy treatment and mothers directly treating the child suffering from leukemia. The exclusion criteria of this study were unhealthy mothers and mothers who could not read and write.

The variables in this research were the family factor (motivation, cognition, perceived threat, structure \& family function, stress, coping, social support, care receiver impairment, competing role demands, caregiving activities), nurse factor (empowering, enabling, supporting) patient (age, child status, duration of illness, disease severity). The data was collected through questionnaires. The questions in the questionnaire used in this study have been tested for their validity and reliability. The validity of each item was done by the Pearson Correlation test using a significance level of 0.005 . The reliability of the items was tested using Cronbach's Alpha.

The questionnaire in this study was developed based on the concept of supporting theories. The indicator instrument of the family factor was developed based on the supporting theoretical concepts. Data related to motivation was measured using a Likert scale questionnaire, made by the researchers themselves based on the indicators of Abraham Maslow's theory. Cognitive data collection was measured based on the family's trust in the ability to treat childhood leukemia. The instrument used to collect the confidence data was done using a Self Efficacy instrument from Albert Bandura. Data relating to perceived threats was measured using a self-made questionnaire by the researchers based on the concept of the Health Belief Model (HBM). Data relating to family structure and function were measured using a FAD (Family Assessment Device) questionnaire. Data related to stress was measured using the Zung Self-Rating Anxiety Scale (SAS / SRAS). Data relating to family coping was measured using a checklist list of variables contained in the Family Coping Index (FCI) Nursing Service and Johns Hopkins School of Hygiene and Public Health, which includes the competence of the family in the care of their sick family members. Data related to social support was measured using a self-made questionnaire by the researchers based on the Friedman \& Marylin family assessment concept (2003). Data relating to the parenting demands was measured using the caregiver reaction assessment.

Data collection related to the nursing factor (empowering, enabling, supporting), which can influence family empowerment, was measured using a self-made instrument by the researcher based on the family centre care concept on nursing care in children and a modification of the Family Empowerment Scale questionnaire. Data relating to Filial Value was measured using a filial value scale. Data related to the family's ability to treat children with leukemia used a revised Caregiving Appraisal Scale (RCAS) questionnaire consisting of 27 -items in a self-administered questionnaire, using a 4-point Likert scale for item responses (Lee, Friedmann, J.Picot, Ann Thomas, \& Ja KIm, 2007). Data relating to Perceived Health was measured using the Questionnaire Health Status Questioner (HSQ-12). Data relating to personal growth measurements was measured using the Personal Growth Initiative Scale (PGIS) questionnaire from Cristhine Robitschek (Robitschek, 1999). Data relating to the Existential Well Being measurements was measured using the Spiritual Well Being Scale (SWBS) questionnaire from Ellison.

The development of the Family-Centered Empowerment (FACE) model was done through focus group discussion activities with informants who played a role in the formation of the FACE model, including the families caring for children with leukemia, and nurses. The data was collected and analyzed using SmartPLS. An ethical test was conducted by team ethics RSUD Dr. Soetomo number 385 / Panke.KKE / V / 2017 dated: May 30, 2017. 
Table 1 - Validity test results showing the development of the model for family-centered empowerment on the family ability of caring for children with leukemia.

\begin{tabular}{|c|c|c|c|c|}
\hline No & Variable & Factor & Outer Loading & Description \\
\hline \multirow[t]{9}{*}{1} & Family Factor & X1.1 Motivation & 0.692 & Valid \\
\hline & & $\begin{array}{c}\text { X1.2 Cognition } \\
\text { X1.3 Perceived Threat }\end{array}$ & $\begin{array}{l}0.799 \\
0.870\end{array}$ & $\begin{array}{l}\text { Valid } \\
\text { Valid }\end{array}$ \\
\hline & & X1.4 structure \& family function & 0.325 & In Valid \\
\hline & & X1.5 Stress & -0.188 & In Valid \\
\hline & & X1.6 coping & 0.596 & Valid \\
\hline & & X1.7 Social Support & 0.767 & Valid \\
\hline & & X1.8 Care receiver impairment & 0.672 & Valid \\
\hline & & X1.9 Competing Role Demands & 0.589 & Valid \\
\hline & & X1.10 Caregiving activities & 0.645 & Valid \\
\hline \multirow[t]{4}{*}{2} & Patient Factor & X2.1 Age & 0.817 & Valid \\
\hline & & X2.2 Child Status & 0.789 & Valid \\
\hline & & X2.3 Duration of illness & 0.133 & In Valid \\
\hline & & X2.4 Disease severity & 0.856 & Valid \\
\hline \multirow[t]{3}{*}{3} & Nurse Factor & X3.1 Empowering & 0.899 & Valid \\
\hline & & X3.2 Enabling & 0.875 & Valid \\
\hline & & X3.3 Supporting & 0.879 & Valid \\
\hline \multirow[t]{3}{*}{4} & Filial Value & X4.1 Responsibility & 0.914 & Valid \\
\hline & & X4.2 Respect & 0.883 & Valid \\
\hline & & X4.3 Care & 0.831 & Valid \\
\hline \multirow[t]{2}{*}{5} & Family Appraisal & X5.1 Challenge & 0.924 & Valid \\
\hline & & X5.2 Stressor & 0.706 & Valid \\
\hline \multirow[t]{3}{*}{6} & Caregiver outcome & Y1.1 Perceived Health & 0.866 & Valid \\
\hline & & Y1.2 Personal growth & 0.869 & Valid \\
\hline & & Y1.3 Existential wellbeing & 0.687 & Valid \\
\hline \multirow[t]{3}{*}{7} & Child Indicator & Y2.1 Nutrition Status & 0.801 & Valid \\
\hline & & Y2.2 Secunder Infection & 0.893 & Valid \\
\hline & & Y2.3 Frequecies of Bleeding & 0.746 & Valid \\
\hline
\end{tabular}

Table 2 - Reliability test result on the development of the model for family-centered empowerment on the family ability of caring for children with leukemia.

\begin{tabular}{lcccc}
\hline No & Variable & Chronbach Alpha & $\begin{array}{c}\text { Composite } \\
\text { Reliability }\end{array}$ & Description \\
\hline 1 & Family Factor & 0.508335 & 0.8905 & Valid \\
2 & Patient Factor & 0.675922 & 0.8621 & Valid \\
3 & Nurse Factor & 0.776507 & 0.9125 & Valid \\
4 & Family Appraisal & 0.676337 & 0.8041 & Valid \\
5 & Filial Value & 0.768920 & 0.9088 & Valid \\
6 & Child Indicator & 0.664848 & 0.8555 & Valid \\
7 & Caregiver outcome & 0.650083 & 0.8461 & Valid \\
\hline
\end{tabular}

Table 3 -Hypothesis test results in relation to the development of the model for family-centered empowerment on the family ability to care for children with leukemia.

\begin{tabular}{clcccc}
\hline No & \multicolumn{1}{c}{ Variable } & $\begin{array}{c}\text { Path } \\
\text { Coefficient }\end{array}$ & $\begin{array}{c}\text { Standar } \\
\text { Deviation }\end{array}$ & T Statistic & Explanation \\
\hline 1 & Family Factor $->$ Filial Value & 0.315307 & 0.082952 & 3.8011 & Significant \\
\hline 2 & Family Factor $->$ Caregiver outcome & 0.083559 & 0.075237 & 1.1106 & No significance \\
\hline 3 & Patient Factor $->$ Filial Value & 0.054482 & 0.077104 & 0.7066 & No significance \\
\hline 4 & Patient Factor $->$ Caregiver outcome & -0.164653 & 0.065742 & 2.5046 & Significant \\
\hline 5 & Nurse Factor $>$ - Filial value & 0.464863 & 0.070538 & 6.5903 & Significant \\
\hline 6 & Nurse Factor $>$ Caregiver outcome & 0.053407 & 0.091932 & 0.5809 & No significance \\
\hline 7 & Family Apprasial -> Caregiver outcome & 0.232694 & 0.083830 & 2.7758 & Significant \\
\hline 8 & Filial value $>$ - Family Apprasial & 0.497954 & 0.072752 & 6.8445 & Significant \\
\hline 9 & Filial value $->$ Caregiver outcome & 0.340145 & 0.086861 & 3.9159 & Significant \\
\hline 10 & Caregiver outcome -> Indicator & 0.288713 & 0.075624 & 3.8177 & Significant \\
\hline
\end{tabular}

\section{RESULTS}

In this study, the outer model test was evaluated by performing the validity and reliability test on the outer model evaluated by the statistical $\mathrm{T}$ score. The validity of the test of the model can be seen from the value of outer loading in Table 1 . Table 1 shows that there are 2 invalid indicators (Structure and function of family $=0.325$, Stress $=-0.188$, illness length $=$ 0.133 ) and 25 valid indicators with outer loading values $>0.5$. The value of outer loading in the family factor consists of motivation (0.692), cognition (0.799), perceived threat (0.870), coping (0.596), social support $(0.767)$, care receiver impairment 
(0.672), competing role demands (0.589) and caregiving activities (0.645). The factors of the patient consist of the indicators of age (0.817), child status (0.789) and disease severity (0.856). The nurse factor consists of empowering (0.899), enabling (0.875) and supporting (0.879). Filial value consists of the indicators of responsibility (0.914), respect (0.883), and care (0.831). Family appraisal consists of the challenge indicator (0.924) and stressors (0.706).

Table 2 shows the reliability test results of the model. The reliability test results can be seen from the Cronbach's Alpha and composite reliability values. The construct or variable is said to be reliable when the value of the composite variable $>0.7$. The value of Cronbach's lpha > 0.6. (0.862), nurse factor (0.912), filial value (0.908), family appraisal $(0.804)$, family ability (0.846) and child indicator (0.855) were all satisfied.

Table 3 shows the results of the hypothesis test. It is said that there is an influence if the value of variable $\mathrm{T}>1$. Based on Table 3 , it can be seen that there is a significant influence between the family factors and filial value ( $\mathrm{T}=3.801)$, there is influence from the patient factor on caring ability $(\mathrm{T}=2,504)$, there is an influence from the nurse factor on filial value $(\mathrm{T}=$ $6,590)$ family appraisal on nursing ability $(\mathrm{T}=2.776)$, filial value on family appraisal $(6,844)$, filial value on caring ability ( $\mathrm{T}=3.92)$ ), and caring ability towards the child indicator $(\mathrm{T}=3.82)$. An analysis of the test results of the model development can be seen in Figure 1.

The recommendations of the FGD results are as follows: (1) to increase family motivation in caring for children with leukemia by providing assistance to the family; (2) teaching the family to form positive coping methods when giving care to children suffering from leukemia; (3) to enhance communication between nurses and families to remind one another in terms of the actions that are always performed when caring for children with leukemia; (4) providing family health education on psychospiritual needs to increase family confidence in caring for children with leukemia; 5) preparation of guidelines for nursing interventions in providing assistance to the family for family empowerment in caring for children leukemia and (6) health education about specific things that must be known by the family when treating childhood leukemia that is easy to understand by the family. All of the results of this study were integrated into a module as a guide to improve family empowerment when treating childhood leukemia.

\section{DISCUSSION}

\section{Family factors forming family empowerment}

Family factors in the application of family-centered care are formed by the indicators of motivation, cognition, perceived threat, coping, social support, care receiver impairment, competing role demands, and caregiving activities. The family is the main source of the child's support when providing stability to children in times of childhood trauma. Family-to- family support can benefit the mental health status of the mothers of children suffering from chronic diseases (Academy, Pediatrics, \& Care, 2018; Ireys, Chernoff, Devet, \& Kim, 2015). Alhani et al (2003) explained that in order to empower families in improving optimal health, any response must involve the 3 dimensions of motivation, cognition, and the basic properties of the individual. Intrinsic motivation involves the positive and valuable experience that individuals derive directly from a task. Individuals try to motivate themselves by establishing confidence in the action that is to be taken, and planning the action to be realised. Motivation is needed to improve family empowerment when treating child leukemia.

Another dimension in the family factors that makes up family-centered care is cognition. Cognition, in this case, is the family knowledge of treating childhood leukemia. Knowledge is the result of knowing, and this occurs after the person senses a particular object. Sensing occurs through the human senses of the sense of sight, hearing, smell, taste, and touch. Much of human knowledge is obtained through the eyes and ears (Notoadmodjo, 2003). Knowledge can also be defined as the facts or information that we think is correct based on thoughts involving empirical testing (the thought of phenomena being observed directly) or based on other thought processes such as giving logical reasons or problem-solving (Hidayat, 2007). Family knowledge can provide information for the family to improve its ability to care for children with leukemia.

The perceived threat dimension (perceived threat) is also one of the basic family building factors involved in fostering empowerment. Families perceiving threats to the severity of the condition of childhood illness can be a matter of increasing the ability of the family to care for children with leukemia. Threats encourage individuals to take preventive or cure measures, but too much of a threat creates fear that impedes action by the individual feeling helpless (resigned). It supports this research that perceived threat (perceived threat) by the family is an indicator of the formation of a sense of empowerment in the family, in improving the ability of the families to treat childhood leukemia. Another indicator of empowerment is family coping. Family coupling in relation to treating patients with chronic disease is the family adaptation ability in the face of severe and long-term stressors (chronic) due to one family member suffering from chronic illness. According to Mc Cubbin (2001), when a family member suffers from chronic illness or disability, including mental disorders, the family should provide long-term care and must continue to support the patient to perform their daily routine activities.

Family support is the attitude, action, and acceptance of the family to its members. Family members are seen of as an integral part of the family environment (Friedman \& Marylin, 2010). Family support is the verbal information, targets, real assistance or behaviour provided by people who are 


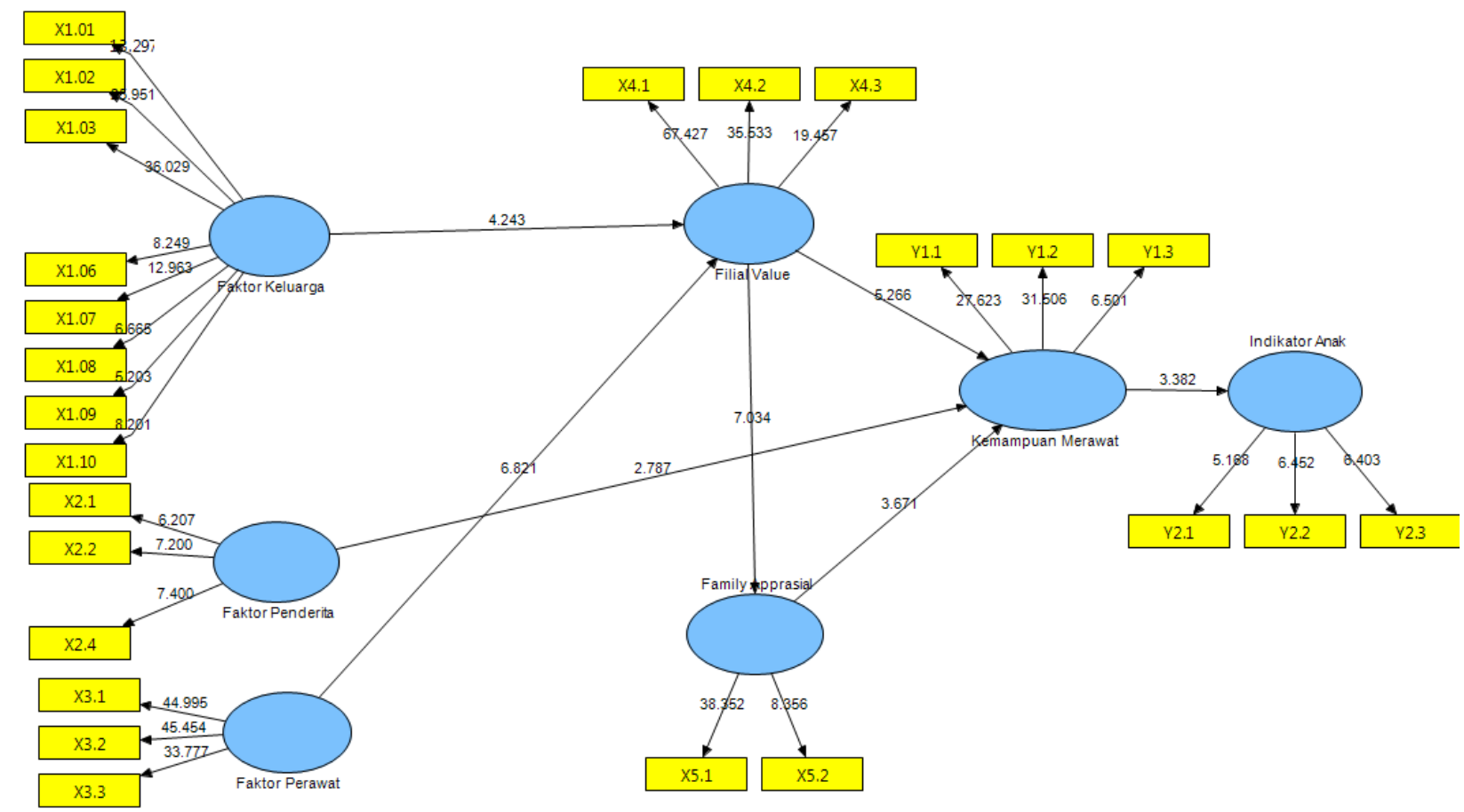

Figure 1: Analysis test results on the development of a model for family-centered empowerment on the ability of the family to care for children with leukemia.

familiar with the subject in their social environment or in the form of attendance and things that can provide emotional support or influence the behaviour of acceptance. Low social support is the support of families of people with chronic diseases that can affect individual behaviour, such as increased stress, helplessness and despair. These things ultimately reduce health status. Decreased health status means a decrease in the quality of life of the patient (Antari, 2013).

Caregiver demands is another dimension of family factors as an indicator of the formation of familycentered empowerment, consisting of care receiver impairment, competing for role demands, and caregiving activities. The demands of family care in this study were mostly in the moderate category, indicating that family reactions in providing care to children with leukemia are still complex. This is in accordance with the opinion of Given (1992) in that the family reaction to caring for sick family members is complex and may vary over time. The caregiver's reaction results from an effective assessment of the existing parenting tasks, the effort being made, the status or needs of the patient and the care environment. Age, gender, cultural background, ethnicity, socioeconomic status, educational level, personal health, and family dynamics work together as an integral factor in predicting caregiver reactions to demanding roles (Baider \& Bengel, 2001; Hagedorn et al, 2000; Langer, Abrams, \& Syrjala, 2003; Northouse et al, 2000). The results of Govina et al. (2015) also explain that the burden of familyperceived care is related to mood, the difficulty of parenting, family status, employment status and past experience. The nurturing burden that the family perceives in treating the child with leukemia becomes an intervention that should be done by empowering the family in order to increase their ability to caring for their child suffering from leukemia.

\section{Patients factors forming family empowerment}

Family-centered care is formed by the indicators of age and child status, the duration of treatment and the severity of the disease. The results of this study are consistent with the study by Pott \& Mandleco (2012), who suggested that the experience of suffering from an illness is very confusing for children, especially for children who have cognitive development skills that are not enough to understand and help children to respond to stress. The presence of the stress of hospitalisation that occurs in children will affect the parents. Research by Franck et al. (2015) explains that the hospitalisation process causes stress for the elderly. Anxiety and depression in the elderly that occurs during hospitalisation is associated with negative coping mechanisms and post-traumatic stress symptoms.

If the child is sick, the parents also feel the pain experienced by the child (Wong, Hockenberry, Winkelstein, \& Wilson, 2009). The well-being of the caregiver depends on the patient's condition and the individual characteristics of the caregiver (Weitzner et al, 1999). Families who care for children with leukemia should be able to know about the condition of their children so that the families are more vigilant in caring for children with chronic pain conditions. 


\section{Nurse factors forming family empowerment}

The nurse factor in the application of familycentered care is formed by the indicators of empowering, enabling, and supporting. A nurse is a member of a health team working with both the children and their parents (Supartini, 2004). Florence Nightingale (in Priharjo, 2008) stated that a nurse is concerned with maintaining the patient's condition in response to the health problems that he or she is experiencing. According to Ellis \& Hartley (1980, in Priharjo, 2008), a nurse is a person who cares for and protects the sick, elderly and wounded. A major focus in nursing services is the promotion of health and disease prevention in relation to family-focused and therapeutic care. The concept underlying the cooperation between the family and the nurse is that the nurse facilitates the family in remaining active in the nursing care of their child in the hospital and empowers the family's knowledge and skill related to the care of the child in the hospital (Supartini, 2004). Family-centered nursing explains that nursing skills are needed to provide family nursing care, thus enabling family members to achieve improved health of all family members. This leaves the families able to address health problems (Friedman \& Marylin, 2010). This is in accordance with the results of this study, in that the nurse indicator becomes the determining factor in growing the family's basic values (filial value) so then the family can finally empower themselves in treating the child's chronic condition, in this case, leukemia.

\section{Family-Centered Empowerment (family filial values) on family appraisal}

The results of the statistical tests show that filial value (base value) as a form of family-centered empowerment significantly affects family appraisal (family assessment) in the ability to care for children with leukemia. Family filial values are indicators of the formation of empowerment within the family, which consists of the indicators of responsibility, respect and care. Empowerment is an ongoing process to improve people's ability and independence in improving their standard of living. The process is done by generating their empowerment, in order for them to improve their lives on their own strengths. Gibson defines empowerment as a social process; recognising, promoting and enhancing people's ability to find their own needs, solving their own problems and mobilising the resources needed to control their lives (Graves, 2007). Family empowerment is a mechanism that enables the transformation of the family capacity as a positive impact of family-centered nursing orders, health promotion measures and cultural suitability that influences treatment and family development (Graves, 2007). Empowerment is defined as the process of discovery and the development of the personal capacity to be responsible for their life because they have the necessary knowledge and resources to acquire and apply reasoned decisions and sufficient experience to evaluate the effectiveness of decisions (Masoodi et al., n.d).

The indicators of family appraisal formed in this study are challenges and stressors. The family assessed whether the treatment of a children with leukemia was a challenge or if it became a stressor for the family. Family disease assessment is defined as the family's trust when assessing and treating illness (Doherty, 2002). The family has an important role in the process of disease assessment and treatment. Family assessment establishes the value, purpose, and priority of the family members in response to disease.

The above supports the results of this study, in that the basic values of a family as a form of family empowerment can empower families further when providing a positive family appraisal.

\section{Family-Centered Empowerment (family filial value) and the family ability to care for childhood leukemia}

Family filial values as a family-centered empowerment builder significantly affect the ability of the families to care for children with leukemia. Filial values are the attitudes and beliefs about parental responsibility on the health of their children. Confidence and commitment to maintaining traditional values can influence the caregiver's motivation to provide care to their child. There are 3 dimensions in measuring filial value: 1) a sense of parental responsibility when caring for the child; 2 ) respect and admiration of the parents towards their children and 3) the desire of the parents to care for their children. These three dimensions of filial value are expected to: 1) alter how parents value the demands of parenting, whether as a challenge or stressor; 2) contribute to the resources available to overcome the sense of purpose and strong meaning associated with giving back to the parents; 3) influence access to family resources and the use of community resources and 4) indirectly affect the resource outcomes and assessments (Jones et al., 2011).

People are able to change previous behaviours and display their abilities according to the situational needs (Popp et al., 2015). The Calgary intervention in the cognitive domain is one of the enabling factors of behaviour formation. Knowledge and attitude also plays a role as a predisposing factor (Notoatmodjo, 2003). Knowledge of successful cancer treatment will bring out a response in the respondents in the form of a positive attitude. A positive attitude will be reflected in the individual's behaviour when applying the cancer treatment. The act of care from the families with good cancer treatment being conducted in the family is in line with the concept of cybernetics, and the ability to organise themselves through the feedback process. Intrapersonal systems can be seen in the feedback that occurs due to the behaviour of a person that influences and is influenced by the behaviour of another. Actions in family cancer care can also be influenced by the availability of the 
facilities owned by the family and the family motivation in applying care.

\section{The family's ability as an indicator of child health status}

The results of statistical tests showed that the ability of the family significantly influences the indicator of child health status. The family's ability, in this study, includes the indicators of family care outcomes in relation to treating children with leukemia, which in consists of the indicators of perception about healthy, personal and family growth, and the existence of prosperous conditions. In this study, most of the respondents were in the medium category. The indicators of child health status in this study were the nutritional status of the child, the incidence of secondary infection, and the occurrence of bleeding. The results showed that most of the child health indicators were in the medium category. This indicates that the health indicators of children with leukemia can be seen from the increased ability of the families in treating children leukemia. Family ability in this study includes the indicators of family care which consists of perceived health, personal growth, and existensial well-being. The ability of families to care for children with leukemia increases in line with the increase in family appraisal when giving an assessment of themselves, in relation to caring for children with leukemia being a challenge for them, as they want to be able to do their best for the health of their child. Familycentered empowerment will improve the family's ability to provide an appraisal. Family-centered empowerment is the process of parental involvement to improve their ability to care for their child (Olin et al., 2010). The family's ability to care for a child with leukemia requires an effort by the health care provider so then the family's ability to care for their child with leukemia increases and the child's health indicators can be improved.

\section{CONCLUSION}

The family's ability to care for their child with leukemia can be enhanced by fostering a sense of empowerment. Family-centered empowerment can be maximised to improve their positive outcomes, which in turn will improve the indicator of health status in relation to the child with leukemia. Based on the results of this study, the family factors, patient factors and nurse factors have a direct influence on family empowerment (responsibility, respect, and care) when treating children with leukemia.

The existence of a sense of empowerment in the family can increase certain behaviours when doing a family appraisal of their ability to care for their child with leukemia. The importance of family appraisal has a role in the efforts undertaken to improve the ability of families to treat children with leukemia. This is evidenced by its role in facilitating family empowerment before establishing positive care outcomes. It is known that if the family filial values are strong, then it will affect the family appraisal so that ultimately, the ability of the family to care for their child with leukemia increases. Increased family ability will affect the child's health indicators.

\section{REFERENCES}

Academy, A., Pediatrics, O. F., \& Care, F. (2018). Committee on Hospital Care, 112(3).

Alhani, F., Niknami, S., Kimiyagar, S., Kazem, N., \& Heidarnia, A. (2003). Family-centered empowerment model and assess its impact on the prevention of iron deficiency anemia in adolescent girls. Journal of Birjand University of Medical Sciences, 8(4), 9-15.

Baider, L., \& Bengel, J. (2001). Cancer and the spouse : gender-related differences in dealing with health care and illness, 40,115-123.

Chiu, M. Y. L., Wei, G. F. W., Lee, S., Choovanichvong, S., \& Wong, F. H. T. (2013). Empowering caregivers: impact analysis of FamilyLink Education Programme (FLEP) in Hong Kong, Taipei and Bangkok. The International Journal of Social Psychiatry, 59(1), 28-39. https://doi.org/10.1177/0020764011423171

Deatrick, J. A., \& Knafl, K. A. (1990). Management behavior: Day-to day adjustments to childhood chronic condition. Journal of Pediatric Nursing, 5, 15-22.

Doherty, W. J. (2002). Family Health Social Work Practice: A AMcro Level Approach. (J. T. Pardeck, Ed.). United State of America: AUBURN HOUSE, Westport, Connectut, London.

Dunst, C. J. (2011). Family-Centered Practices, Parent Engagement, and Parent and Family Functioning.

Elcigil, A., \& Conk, Z. (2010). Determining the Burden of Mother with Children Who Have Cancer. ED 3: DEUHYO.

Franck, L. S., Wray, J., Gay, C., Dearmun, A. K., Lee, K., \& Cooper, B. A. (2015). Predictors of parent posttraumatic stress symptoms after child hospitalization on general pediatric wards: A prospective cohort study. International Journal of Nursing Studies, 52(1), 10-21. https://doi.org/10.1016/j.ijnurstu.2014.06.011

Friedman, \& Marylin, M. (2010). Buku Ajar Keperawatan Keluarga Riset, Teori, dan Praktik. (E. Tiar, Ed.) (5th ed.). Jakarta: EGC.

Govina, O., Kotronoulas, G., Mystakidou, K., Katsaragakis, S., Vlachou, E., \& Patiraki, E. (2015). Effects of patient and personal demographic, clinical and psychosocial characteristics on the burden of family members caring for patients with advanced cancer in Greece. European Journal of Oncology Nursing, 19(1), 81-88. https://doi.org/10.1016/j.ejon.2014.06.009

Graves, K. . (2007). Family Empowerment as a Mediator between Family Centered system of care and changes in Child Functioning: identifying an Important mechanism of change. Washington: Springer Science and Business Media.

Ireys, H. T., Chernoff, R., Devet, K. A., \& Kim, Y. (2015). 
Maternal Outcomes of a Randomized Controlled Trial of a Community-Based Support Program for Families of Children With Chronic Illnesses, 155(July 2001), 771-777.

Johansson, A. (2006). EMPOWERMENTAL NURSING Experiences of Empowerment and Disempowerment Made by Patients in Need of Long Term Nursing.

Jones, P. S., Winslow, B. W., Lee, J. W., Burns, M., \& Zhang, X. E. (2011). Development of a caregiver empowerment model to promote positive outcomes. J.Fam.Nurs., 17(1552-549X (Electronic)), 11-28. https://doi.org/10.1177/1074840710394854

Lee, J., Friedmann, E., J.Picot, S., Ann Thomas, S., \& Ja KIm, C. (2007). Korean version of the Revised Caregiving Appraisal Scale: a translation and validation study. Journal of Advanced Nursing, 59(4), 407-415. https://doi.org/10.1016/j.biotechadv.2011.08.02 1.Secreted

Masoodi, R., Alhani, F., Moghadassi, J., Ghorbani, M.,

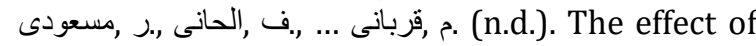
family-centered empowerment model on skill, attitude, and knowledge of multiple sclerosis caregivers. Journal of Birjand University of Medical Sciences.

Olin, S. S., Hoagwood, K. E., Rodriguez, J., Ramos, B., Burton, G., Penn, M., ... Jensen, P. S. (2010). The application of behavior change theory to familybased services: Improving parent empowerment in children's mental health. Journal of Child and Family Studies, 19(4), 462-470. https://doi.org/10.1007/s10826-009-9317-3

Popp, J. M., Conway, M., \& Pantaleao, A. (2015).
Parents' Experience With Their Child's Cancer Diagnosis: Do Hopefulness, Family Functioning, and Perceptions of Care Matter? Journal of Pediatric Oncology Nursing, 32(4), 253-260. https://doi.org/10.1177/1043454214563404

Pott, N. L., \& Mandleco, B. L. (2012). Pediatric Nursing Caring for Children and Their Families (third edit). USA: Delmar.

Priharjo, R. (2008). Konsep \& Perspektif Praktik Keperawatan Profesional (Edisi 2). Jakarta: EGC.

Robitschek, C. (1999). Personal Growth Initiative Scale (PGIS), 6. https://doi.org/http://dx.doi.org/10.1037/t042 61-000

Supartini, Y. (2004). Konsep Dasar Keperawatan Anak. Jakarta: EGC.

Weitzner, M. a., Jacobsen, P. B., Wagner, H. J., Friedland, J., \& Cox, C. (1999). The Caregiver Quality of Life Index-Cancer (CQOLC) scale: development and validation of an instrument to measure quality of life of the family caregiver of patients with cancer. Quality of Life Research, 8(1), 55-63. https://doi.org/10.1023/A:1026407010614

Wong, D. L., Hockenberry, M., Winkelstein, M., \& Wilson, D. (2009). Buku Ajar Keperawatan Pediatrik. In A. Hartono, S. Kurnianingsih, \& Setiawan (Eds.), Jakarta, EGC.

Wright, L., \& Leahey, M. (2000). Nurses and families: a guide in family assessment and intervention. Philadelphia: Davis.

Wuest, J., \& Stern, P. . (1991). Empowerment in Primary Health care: The $\mathrm{Cg}=$ hallenge for Nurses. Qualitative Health Research, 1, 80-99. 